\title{
Moguer en la época de la Restauración: la figura de Manuel Burgos y Mazo
}

\author{
MARIA JESÚS MORENO DE HINESTROSA
}

Al elegir el tema para esta comunicación me pareció interesante encuadrar el estudio de algunos aspectos de la vida de' Manuel Burgos y Mazo dentro del panorama general de la política municipal en Moguer durante la época de la Restauración. Aun siendo consciente de la existencia de trabajos valiosos sobre este político, mi condición de moguereña me ha impedido evitar la tentación de acercarme a su vida y a su obra, arriesgándome a repetir algunas de las ideas que ya se conocen de este personaje.

Así pues, la exposición se inicia con un breve resumen de la vida política local en el Moguer de la Restauración, y ya en la segunda parte de esta comunicación y realmente la que constituye el tema de la misma son algunos aspectos de la vida de Manuel de Burgos, moguereño que vivió en estas fechas y cuya dedicación a la política lo ha convertido en un personaje conocido fuera de su lugar de nacimiento. Esto explica que haya querido acercarme a su vida y a su obra.

La política moguereña en la época de la Restauración presenta características similares a las de otras zonas de España y, sobre todo, de Andalucía. Un reducido número de familias acomodadas, además de tener una buena situación económica y social, controlaban el :poder político. Esto se traducía fundamentalmente en que ocupaban los puestos de la Corporación municipal, así mismo formaban parte de la Junta de Vocales Asociados y de la Junta Pericial. Los miembros de estas familias rotaban de un cargo a otro, de forma que son los mismos apellidos los que encontramos en uno u otro organismo a lo largo de estos años. Desde sus puestos adoptaban medidas y decisiones que determinaban infinidad de cuestiones de la vida de los vecinos.

En este panorama que hemos presentado sobre la política municipal en la época municipal de la Restauración, no se evidenciaba la presencia en la localidad de Manuel de Burgos y Mazo, a pesar de que fue uno de los moguereños más destacados de su época, ya que jugó un papel importante en la política tanto a nivel provincial como nacional. Si apare- 
cen entre los componentes de la Corporación moguereña algunos miembros de su familia, entre ellos su hermano Augusto de Burgos y Mazo.

A continuación vamos a aproximarnos a algunos aspectos de su personalidad, utilizando como fuentes de información el testimonio de personas que lo conocieron y la lectura de algunas obras escritas por él mismo.

Comenzaremos exponiendo que Manuel de Burgos y Mazo nació en 1.862 en Moguer y murió en 1.946 en esta misma localidad ${ }^{1}$. Fue hijo de uno de los propietarios agrícolas más importantes de la localidad, lo que le permitió disfrutar de una situación económica buena. Esto a su vez le permitió adquirir un buen nivel cultural, lo cual no era fácil para la mayoría de los moguereños. Manuel de Burgos pasó los primeros años de su vida en Moguer, donde realizó sus estudios primarios. La posición económica de su familia le permitió trasladarse a Sevilla, donde lo internaron en el colegio de los jesuitas para que cursase el Bachillerato. En la Universidad de esta misma ciudad se licenció en Derecho.

Sus estudios, sus ideas y sus inquietudes le llevaron a dedicarse a la política, teniendo un papel destacado en el partido conservador y ocupando el cargo de Ministro de Gracia y Justicia en 1.915 y 1.917 , y el de Ministro de la Gobernación en 1.919. Gracias a algunas obras que él escribió hemos conocido muchas de sus ideas y de sus experiencias, las cuales expondremos en esta comunicación.

No obstante, vamos a comenzar reseñando algunas de las opiniones que sus paisanos tenían sobre él y que han llegado hasta nosotros. No cabe duda que Manuel Burgos era un moguereño destacado en su época, suscitando, como le sucede a muchos personajes de la vida pública opiniones contradictorias. Su preparación cultural, sus cargos políticos y su influencia despertaban admiración en una población donde la mayoría de los vecinos eran pobres, incultos y sin ninguna preparación política.

Los moguereños lo recuerdan como una persona importante, pero que tenía como virtud la sencillez. Como muestra de ello comenta que era accesible para quien quisiera hablar con él, estando abierta las puertas de su casa para muchos moguereños que le quisiera pedir un favor. En este sentido, también señalan que era una persona muy formal, muy puntual y de gran corrección en su trato.

Junto a esta imagen también conserva la memoria popular otra muy distinta. Manuel Burgos iba al campo en muchas ocasiones a realizar faenas agrícolas. Especialmente recuerdan que sus estancias en Moguer gustaba de ir al campo a podar viñas, hecho que llamaba la atención puesto que con su situación económica y su nivel cultural era extraño ver a alguien haciendo este tipo de tareas.

(1) BLEIBERG, G.: Diccionario de Historia de España.Tomo 1, Madrid, 1986 
Otra opinión que hemos recogido entre los moguereños que lo conocieron es que su dedicación a la política le perjudicó económicamente, ya que al no ocuparse totalmente de la administración de sus propiedades acabó perdiendo muchas de ellas y el patrimonio familiar que había heredado fue disminuyendo.

Por último, tenemos que reseñar otra idea que los paisanos de Manuel Burgos fueron formándose de él, a raíz de los puestos políticos destacados que ocupó, siendo esta idea de índole más negativa que las expuestas hasta ahora. Aún se comenta actualmente en Moguer que Manuel Burgos podía haber realizado una labor más favorable para su pueblo y piensan que en cierta medida se desentendía de los graves problemas que la localidad estaba viviendo. Hay dos temas sobre los que se crítica la actuación de Manuel Burgos. El primero de ellos es el de la capitalidad de la provincia, que según los moguereños recayó en Huelva en vez de en Moguer porque Manuel Burgos opinó en Madrid que su pueblo no necesitó ser capital porque ya era una localidad importante y próspera. Naturalmente la crítica de los moguereños no tiene ninguna razón, puesto que la división de España en provincias y la designación de sus capitales fue hecha con anterioridad al nacimiento del señor Burgos.

El otro asunto sobre el que los moguereños tienen quejas del interés mostrado por Manuel Burgos es el del trazado del ferrocarril que se hizo por San Juan del Puerto, dejando de lado a Moguer, lo que trajo como consecuencia el aislamiento y la marginación de nuestra localidad. También en este caso se piensa que Manuel Burgos no sólo no intervino en favor de que Moguer quedase incluido en el recorrido de la vía férrea, sino que incluso estuvo en contra de esta idea. Aun resultando difícil demostrar si los hechos ocurrieron así, lo cierto es que desde el punto de vista técnico, el trazado del ferrocarril fue hecho correctamente, y lo que hubiese sido ilógico es que se hubiera proyectado por la otra margen del río Tinto, puesto que así había que vencer más obstáculos geográficos y los costes económicos se hubiesen elevado enormemente.

Así pues, parece que estas dos críticas que los moguereños realizaban a su paisano no tienen ningún fundamento y posiblemente se han ido transmitiendo de generación en generación amparadas por la ignorancia popular. Desde luego, lo frecuente es oír, incluso actualmente, alabanzas respecto a Manuel Burgos y Mazo, ya que no en vano fue uno de los pocos moguereños destacados de su época. Posiblemente sólo compartía esta importancia con Juan Ramón Jiménez al que le unían lazos de amistad. Por este motivo le obsequió en más de una ocasión con obras suyas, las cuales tal como hemos podido comprobar en la biblioteca de Manuel Burgos y Mazo, tenían una dedicatoria personal del poeta. 
Por una nota documental del Archivo Municipal de Moguer conocemos como en 1.919 los moguereños acudieron a pedir ayuda a Manuel Burgos. Para ello organizaron una manifestación popular el día 21 de marzo que partiría a las seis de la tarde de la Plaza de las Monjas en dirección al Ayuntamiento para ser presidida por el Alcalde y Concejales y desde allí dirigirse a casa del señor Burgos con objeto de pedirle que uniese sus esfuerzos a los de la población para conseguir de los poderes públicos la inmediata limpia del río Tinto ${ }^{2}$.

Por tanto, podemos comprobar cómo se contó con Manuel Burgos para este tema que preocupaba bastante a los vecinos, puesto que era importante para resolver los problemas de comunicación a través del río que Moguer estaba teniendo.

Para terminar estas referencias que estamos haciendo sobre el recuerdo que Manuel Burgos y Mazo ha dejado entre sus paisanos me parece interesante apuntar que Moguer le ha dedicado la calle donde se encuadra su casa, de manera que cualquier moguereño conoce desde pequeño el nombre de este político. Quizás por eso me he sentido atraida por su figura y su obra y la he escogido como tema para esta comunicación. Aún hoy, entrar en su casa es acercarse a su persona. Los muebles, las paredes, los cuadros, pero sobre todo su biblioteca hacen presente a este hombre. La lectura de sus libros no sólo ha sido una tarea realizada como historiadora, sino un placer como moguereña.

Traspasando el ámbito local también Manuel Burgos y Mazo era una figura destacada. Como han señalado muchos estudiosos de la política de esta época, bajo su influencia la provincia de Huelva se convirtió en uno de los cacicatos más dóciles y estables de Andalucía. Tan sólo en la década de los veinte disminuyó su poder, siendo esto ya claro con la llegada de la Segunda República ${ }^{3}$. Pero atrás habían quedado muchos años de política activa, años en los que había ocupado cargos importantes, había escrito numerosas obras recogiendo sus experiencias, y sobre todo, eso, una vida llena de experiencias muy distintas de las vividas por el resto de sus paisanos. A continuación recogemos estos aspectos de la vida de Manuel de Burgos y Mazo.

Manuel Burgos ocupó diversos cargos de tipo político, siendo además nombrado en 1.918 miembro de la Real Academia de Ciencias Morales y Políticas. Con este motivo escribió un discurso que fue publicado,

(2) Archivo Municipal de Moguer, Leg. 72. Bandos, Edictos, Pregones, Avisos, Anuncios, Hago Saber. Años 1904-1979 (21-3-1919).

(3) ALVAREZ REY, L. Y RUIZ SANCHEZ, J.L.: Huelva durante la Segunda República: partidos, elecciones y comportamiento político (1931-1936) en Huelva en su Historia,3. Huelva, 1990, ps. 647-9. 
conservándose en la biblioteca particular de la familiar Burgos un ejemplar de esta obra千. En ella, además del discurso de Manuel Burgos también se incluyó la respuesta de un académico a través de la cual hemos podido conocer los puestos públicos que detentó Manuel Burgos, así como los títulos de las obras más importantes que escribió.

Reseñamos a continuación los cargos políticos que desempeñó Manuel de Burgos y Mazo:

- Diputado a Cortes por Huelva desde 1.983, representando luego al distrito de La Palma y después la Circunscripción hasta 1.914 en que fue nombrado senador vitalicio.

- Vicepresidencia del Congreso de los Diputados y Director General de Obras Públicas en 1.903 (G.Silvela)

- Director General de Gracia y Justicia en el Ministerio de Ultramar (Gabinete Azcárraga) en 1.897.

- Director General de Penales en 1.899 (Gabinete Silvela).

- Subsecretario de Gracia y Justicia en 1.901.

- Ministerio de Gracia y Justicia en 1.915 (Gabinete Dato).

- Ministro de Gracia y Justicia en 1.917.

- Ministro de Gobernación en 1.919 (No recogido en la citada obra por ser posterior a su publicación).

Asimismo recogemos los títulos de las obras escritas por Manuel Burgos y Mazo: El otro yo, Martín Alonso Pinzón, Melusina, Intelectuales, Pecado de pensamiento, La arrepentida, La calumnia, Atavismo, El secreto de Agar, Romper el hielo, Teodosio de Goñi y El Cierzo.

Otros trabajos publicados por el político moguereño fueron los siguientes: Mártires de hogaño, La cuestión tradicionalista, La enseñanza del doctorado en Derecho Civil y Canónico, Escritos varios y La socialización del Derecho.

También se citaban algunas de las obras más importantes, en las cuales se encontraban muchas de las ideas de este político, estas obras eran: Influencia del alma colectiva en el Derecho y en las Instituciones jurídicas, Vida política española, Páginas históricas de 1.917 y El problema social y la democracia cristianas.

Por último, y para completar esta relación, nosotros hemos encontrado en la biblioteca del señor Burgos otras obras que también tienen un gran interés para conocer las ideas de su autor. En primer lugar, está la

(4) BURGOS Y MAZO, M. DE: Discurso de ingreso del Excmo. D. Manuel de Burgos y Mazo en la Real Academia de Ciencias Morales y Políticas (22-12-1918) Madrid, 1918. (5) BURGOS Y MAZO, M. DE: El problema social y la democracia cristiana. Barcelona,
1914 . 


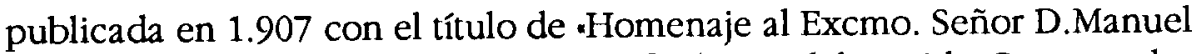
Burgos y Mazo, Diputado a Cortes y Jefe ilustre del Partido Conservador en la provincia de Huelva ${ }^{6}$. En 1.908 se publicaron bajo el título :Escritos varios" distintos trabajos de Manuel Burgos ${ }^{7}$. Igualmente es interesante conocer el iDiscurso leido por el Excmo. Señor D. Manuel de Burgos y Mazo Ministro de Gracia y Justicia en la Solemne apertura de los Tribunales", celebrada el día 15 de septiembre de $1917^{8}$. Muy destacada es la obra .El verano de 1919 en Gobernación., publicada en 1920 y que nos acerca en profundidad a la labor de Manuel Burgos en este ministerio'.

La exposición de las ideas de Manuel Burgos y Mazo vamos a comenzarla señalando una división que el mismo hacía en el año 1908 cuando dividía en dos su etapa como escritor. La primera comprendía desde que salió del colegio hasta el año 1888 cuando estuvo en el partido tradicionalista. La segunda abarca desde el año 1808 hasta el año 1908 , y ya pertenecía al partido conservador. Burgos y Mazo explica que la razón de haberse cambiado de partido fue que los tradicionalistas se habían separado en íntegros y carlistas y él no quería tener ninguna relación con los carlistas ${ }^{10}$.

Ya en el partido conservador Burgos realizó una labor importante organizando el partido de la provincia en los primeros años del s.XX, acabando con la imposición de candidatos cuneros. Como señala Tusell, transcurridos unos años Manuel Burgos controla perfectamente la situación desde su residencia de Moguer, centro de su cacicato ${ }^{11}$.

Comparte su entrega al partido con su tarea de escritor y de estos años nos deja una obra interesante que ya mencionábamos anteriormente. Nos referimos a la titulada El problema social y la Democracia Cristiana, publicada en 1914 y prologada por Eduardo Dato. La presentación que hace Dato en estas primeras páginas es muy acertada, señalando que se trata de una crítica de la doctrina socialista, pero basándose esta crítica en un estudio histórico y documental profundo ${ }^{12}$.

Manuel Burgos en esta obra hace un amplio recorrido por la historia, demostrando una gran preparación cultural. Concretando su opinión sobre la situación en el momento que le tocó vivir, según él la sociedad

(6) Homenaje al Excmo. Señor D. Manuel Burgos y Mazo. Diputado a Cortes y Jefe Ilustre del Partido Conservador en la provincia de Huelva. Huelva, 1907.

(7) BURGOS Y MAZO, M. DE: Escritos varios. Huelva, 1908

(8) BURGOS Y MAZO, M. DE: Discurso leido por el Excmo. Señor Don Manuel de Burgos y Mazo, Ministro de Gracia y Justicia en la Solemne apertura de los Tribunales (15-9-1917), Madrid, 1917.

(9) BURGOS Y MAZO, M. DE: El verano de 1919 en Gobernación. Cuenca, 1920.

(10) BURGOS Y MAZO, M. DE: Escritos... op. cit.,pág.5.

(11) TUSELL, J.: Oligarquía y caciquismo en Andalucía (1890-1923), Barcelona, 1976.

(12) BURGOS Y MAZO, M. DE: El problema..., op.cit. ps. V-XV. 
vivía momentos de angustia y malestar, a la vez que sentía que se atacaban ideas fundamentales como la de patria, Dios, familia y propiedad. Para el autor, frente a esta agitación febril del socialismo están surgiendo en algunos países propaganda y organizaciones sociales católicas, existiendo además una amplia legislación social promovida más por los católicos o los partidos conservadores que por los socialistas ${ }^{13}$.

En un discurso pronunciado en 1917, el señor Burgos manifiesta que se está viviendo en una especie de socialismo de estado, no siendo ya $\tan$ fuertes los principios individualistas ${ }^{14}$. Al mismo tiempo, afirma que el legislador tiene en cuenta el alma colectiva de un pueblo a la hora de realizar su labor ${ }^{15}$. Manuel Burgos reconoce que hay un enfrentamiento entre las clases directoras y los proletarios, siendo necesario la concordia entre ambas y que reconozcan sus derechos y deberes respectivos, pero el socialismo y anarquismo, se encargan de impedir esa solución ${ }^{16}$. Así pues para Burgos estas dos organizaciones no ayudan al entendimiento social, llegando a veces incluso a hacer reivindicaciones de algunos temas que ya están resueltos, como por ejemplo el reconocimiento de la jornada de ocho horas.

En su obra :El verano de 1919 en Gobernación * Burgos expone algunas ideas que considera necesarias para fortalecer el partido conservador puesto que ya no basta el programa de Cánovas y las ideas de éste recogidas en la Constitución de 1876 puesto que han surgido nuevos problemas por la evolución de los elementos sociales. Rechaza la cooperación con el socialismo, considerándolo como un puente de desórdenes para pasar a la anarquía ${ }^{17}$.

Pero además, en este libro se recogen numerosas experiencias que tuvo Burgos y Mazo como ministro de Gobernación, teniendo que hacer frente a numerosos problemas, buscando para cada uno de ellos la salida más adecuada, opinando que el uso de la fuerza resultaba ineficaz. Entre los distintos conflictos que se presentaron destacan las deficiencias sanitarias que se estaban dando en muchas zonas del país y diversas huelgas que llevaron a cabo algunos colectivos.

En el aspecto sanitario dos fueron las principales problemáticas que se presentaron. La primera de ellas fue una epidemia de tifus exantemático en Granada y Almería. La otra fue la huelga de los médicos de beneficencia en Jerez de la Frontera. En ambos casos fue fundamental la interven-

(13) BURGOS Y MAZO, M. DE: El problema ..., op. cit. ps. 1-31.

(14) BURGOS Y MAZO, M. DE: Discurso..., op. cit. ps. 10-12.

(15) BURGOS Y MAZO, M. DE: Discurso..., op. cit. ps. 41-42.

(16) BURGOS Y MAZO, M. DE: El problema..., op. cit. ps. 35-73.

(17) BURGOS Y MAZO, M. DE: El verano..., op. cit. ps. 7-19. 
ción del señor Burgos, el cual mantuvo una continua correspondencia con los gobernadores civiles de las provincias afectadas. De esta manera consiguió solucionar los problemas, imponiendo su autoridad y consiguiendo acuerdos con el personal sanitario implicado en estos temas ${ }^{18}$.

Otros conflictos laborales también se hicieron presentes en este año 1919. Así podemos mencionar como más graves la Huelga General Ferroviária, la Huelga de Mineros y la de Panaderos. Burgos tuvo que hacer frente a esta y otras situaciones de inquietud social y laboral, procurando no hacer uso de la fuerza, porque como ya apuntábamos antes, no creía que esta fuese la solución. Fue necesario hacer negociaciones con estos colectivos y con la patronal implicada en estos conflictos ${ }^{19}$.

En esta misma obra Burgos expone cuál debe ser la actuación del gobierno ante la problemática social entendiendo que es el que tiene que tomar parte en la búsqueda de soluciones mediante una legislación laboral amplia, llevando a cabo reformas sociales e intentando deshacer las conjuras que pretendan romper el orden público ${ }^{20}$. Asimismo, Manuel Burgos y Mazo cierra la redacción de su obra en Moguer con fecha 31 de Diciembre de 1920 recalcando la idea de que se deben aplicar las leyes y la justicia de igual forma para todos ${ }^{21}$.

Por último, vamos a mencionar una obra que publicó con motivo del homenaje que se le tributó a Manuel Burgos y Mazo como jefe del Partido Conservador en la provincia de Huelva, para regalarle, como consta en la introducción, las insignias de la Gran Cruz de Isabel la Católica ${ }^{22}$. El total recaudado fue de 4.034 '20 pesetas, oscilando el importe de las contribuciones entre 0'10 y dos pesetas. Fueron 62 el número de localidades onubenses en las que hubo vecinos que participaron en este homenaje.

La popularidad con la que contaba Manuel Burgos puede justificar en cierta medida su designación para candidato a diputado a Cortes. Tal como señala Tusell al encasillado lo aprueba el Presidente del Consejo de Ministros y Ministro de la Gobernación, comunicándoselo generalmente por telegrama al gobernador, como sucedió por ejemplo en 1907 cuando fue designado Don Manuel Burgos y Don Manuel Martín por el distrito de Huelva ${ }^{23}$.

(18) BURGOS Y MAZO, M. DE: El verano..., op.cit. ps. 261-298.

(19) BURGOS Y MAZO, M. DE: El verano..., op. cit. ps. 361-616.

(20) BURGOS Y MAZO, M. DE: El verano..., op. cit. ps. 305-359.

(21) BURGOS Y MAZO, M. DE: El verano..., op. cit. pág. 617.

(22) Homenaje al Excmo. Sr..., op. cit., ps. 1-5.

(23) TUSELL, J.: Oligarquía..., op. cit., ps. 109-111. 
Tusell publica los resultados electorales de algunos años en los que Burgos y Mazo fue el candidato que más votos obtuvo de todos los que se presentaron por la provincia de Huelva. Así tenemos como ejemplos los años de 1905 y $1910^{24}$.

Nos quedaría por último reseñar algunos aspectos de la vida de Manuel de Burgos y Mazo, los cuales reflejan la popularidad que alcanzó en esta zona, lo que llevaba consigo su participación en estos actos destacados, tanto de tipo cultural como político. Como ejemplo de ello tenemos los que se llevaron a cabo para la conmemoración del IV Centenario del Descubrimiento de América, actos que ya comenzaron a prepararse en la provincia de Huelva en 1891 y que contaron con la presencia de Manuel de Burgos 25 .

Ya en 1892 a Huelva llegaron personalidades importantes con motivo del IV Centenario, entre ellas tenemos que mencionar a la Reina y a Cánovas del Castillo. La visita de la Reina tuvo lugar en el mes de Septiembre, estando presidida la recepción por el señor Burgos, el cual también presidió el Banquete que tuvo lugar en el Hotel Colón, donde según la prensa de la época pronunció un discurso muy brillante ${ }^{26}$.

Posteriormente, el señor Cánovas también visitó Huelva, siendo Manuel Burgos el encargado de dar la bienvenida y de hacer las presentaciones de todas las personalidades que habían acudido a recibir al Presidente del Gobierno ${ }^{27}$.

Para terminar nos gustaría señalar algunas ideas a modo de balance. Indudablemente la dedicación de Burgos y Mazo a la política debió tener momentos fáciles y agradables como los que acabamos de referir, pero otros estarían marcados por las dificultades puesto que desempeñó cargos de responsabilidad política cuando la nación vivía momentos de crisis política y social, en los que en 1917 abundaban las protestas laborales y las huelgas ${ }^{28}$. En muchos de estos caso Burgos tuvo que mediar entre los empresarios y los obreros, no siendo siempre fácil esta mediación como sucedió en la huelga de ferroviarios de Valencia de 1917, cuando era Ministro de Gracia y Justicia ${ }^{29}$.

(24) TUSELL, J.: Oligarquía..., op. cit., pág. 162.

(25) Archivo Diputación Provincial de Huelva. Guía de Huelva y su provincia. Libro 142. Huelva, 1891.

(26) (H)emeroteca (M)unicipal de (S)evilla. La provincia de Huelva (8-9-1892).

(27) H.M.S. La provincia de Huelva (5-10-1892).

(28) ROMERO LARGO, L. Y OTROS: Historia de España. La Restauración. El reinado de Alfonso XIII. Tomo VIII. Madrid, 1990, ps. 477-480. (29) TUÑON DE LARA, M.: El movimiento obrero en la Historia de España. Tomo II. Madrid,
1985, pág. 65. 
La vida política de Manuel Burgos fue perdiendo importancia conforme el sistema canovista fue perdiéndola también y fue quemándose frente a los problemas sociales y económicos que el país tenía ${ }^{30}$.

Ya en los años de la República fue inevitable la disminución, prácticamente total, de la hegemonía que había tenido, y de nada le valieron sus esfuerzos para mantener su posición ${ }^{31}$. Posiblemente debió ser una situación dura y difícil de sobrellevar para una persona que desde joven había entregado su vida a la política.

(30) SECO SERRANO, C.: El sistema político de la Restauración en .Cuadernos de historia 16. Alfonso XII y su época. Madrid, 1985, ps. 14-23.

(31) ALVAREZ REY, L. Y RUIZ SANCHEZ, J.L.: Huelva..., op. cit. pág. 650. 